\title{
MICRORGANISMOS INDICADORES E Salmonella sp. EM SALAMES PRODUZIDOS E COMERCIALIZADOS NA REGIÃO OESTE DO PARANÁ
}

\section{INDICATORS MICROORGANISMS AND Salmonella sp. IN SALAMI PRODUCED AND MARKETED IN THE WESTERN REGION OF PARANÁ}

\author{
Fernando Zocche ${ }^{1}$; Vinicius Cunha Barcellos ${ }^{2}$; Luciano dos Santos Bersot ${ }^{2}$ \\ ${ }^{1}$ Universidade Federal do Pampa - Campus Dom Pedrito- UNIPAMPA - Dom Pedrito- Brasil \\ fernandozocche@ hotmail.com \\ ${ }^{2}$ Universidade Federal do Paraná - Campus Palotina - UFPR - Palotina - Brasil \\ vcbarcellos@ufpr.br; lucianobersot@ufpr.br
}

\begin{abstract}
Resumo
$O$ objetivo deste estudo foi caracterizar microbiologicamente, salames produzidos $e$ comercializados na região oeste do Paraná, através da enumeração de microrganismos indicadores e pesquisa de Salmonella sp. Trinta e quatro $(n=34)$ amostras de salames industrializados foram adquiridas no município de Palotina, situado na região oeste do Paraná, e submetidas à análise microbiológica para enumeração de Staphylococcus coagulase positiva, coliformes totais $\left(35^{\circ} \mathrm{C}\right)$ e termotolerantes $\left(45^{\circ} \mathrm{C}\right)$ e pesquisa de Salmonella sp. Observou-se que $61,8 \%$ das amostras estavam contaminadas com Staphylococcus coagulase positiva além do estabelecido na RDC 12, da ANVISA. Encontrou-se 5,9\% das amostras contaminadas com coliformes termotolerantes e 5,9\% das amostras contaminadas com Salmonella sp. Através da contaminação observada no salame produzido e comercializado na região oeste do Paraná, sugere-se más condições de higiene no momento da fabricação.
\end{abstract}

Palavras-chave: embutidos cárneos; contaminação, higiene

\section{Introdução}

$\mathrm{Na}$ alimentação humana, a carne é a principal fonte de proteínas de alto valor biológico compostas por aminoácidos essenciais (SOUSA, 2000). Por ocasião do abate, pode ser contaminada em contato com pêlo, pele, cascos, conteúdo do trato gastrointestinal, equipamentos e utensílios utilizados no abate, mãos e vestuários do pessoal envolvido no processo e água utilizada para a lavagem de carcaças (LEITÃO, 1984). 
Os embutidos fermentados consistem em uma mistura de carnes e gorduras moídas, cloreto de sódio, nitrito e nitrato, açúcares, especiarias, diferentes tipos de aditivos (de acordo com a necessidade) e um ou mais tipos de culturas iniciadoras (BACUS, 1986). O processo de fermentação caracteriza-se pela multiplicação das culturas iniciadoras (bactérias lácticas) que tem a capacidade de fermentar os carboidratos produzindo ácido lático e, assim, reduzir o pH inicial da mistura cárnea. O ácido lático produzido confere o sabor picante, além de desnaturar proteínas, resultando na textura associada aos produtos fermentados.

De acordo com o Regulamento Técnico de Identidade e Qualidade (BRASIL, 2000), entende-se por salame, o produto cárneo industrializado obtido de carne suína ou mistura de suína e bovina, adicionado de toucinho, condimentos e outros ingredientes, embutido em envoltórios naturais e/ou artificiais, curado, fermentado, maturado, defumado ou não e dessecado. Em relação às características físico-químicas, o salame deve apresentar uma atividade de água (Aw) máxima de 0,92, $40 \%$ de umidade, $35 \%$ de gordura, $1,5 \%$ de carboidratos totais e no mínimo $20 \%$ de proteína.

Dependendo da origem ou processo de obtenção, o salame recebe diferentes denominações, como por exemplo, Salame tipo Italiano ou Milano. Estes produtos são compostos por ingredientes obrigatórios e opcionais seguindo requisitos sensoriais, físico-químicos, microbiológicos e fatores essenciais de qualidade como tempo de maturação e dessecação, forma e peso e acondicionamento (BRASIL, 2000).

A carne está exposta a contaminação desde a sangria até o consumo, e frequentemente está envolvida na disseminação de patógenos causadores de enfermidades aos humanos e aos animais (SOUSA, 2000). Entre os agentes que causam enfermidades transmitidas por alimentos (ETAs), Salmonella, em produtos cárneos, é o principal e constitui sério problema para a saúde pública (PELAYO, 1988), devido a sua sintomatologia. Embora nas últimas décadas algumas bactérias tenham chamado atenção e tenham sido reconhecidas como patógenos emergentes, responsáveis por algumas enfermidades importantes, Salmonella continua ser o principal agente etiológico das ETAs (DOYLE, 1994).

Microrganismos indicadores são aqueles que, quando presentes num alimento, podem fornecer informações sobre ocorrência de contaminação de origem fecal, sobre a provável presença de patógenos ou sobre a deterioração potencial do alimento, além de poderem indicar condições sanitárias inadequadas durante o processamento, produção ou armazenamento. Coliformes totais, termotolerantes e Staphylococcus coagulase positiva são considerados microrganismos indicadores (FRANCO e LANDGRAF, 2002).

Em diversos estudos (REIS et al., 1995; SALGADO et al., 1999; SOUSA, 2000; GIOMBELLI, 2001) há a demonstração que, embora o salame apresente uma combinação de fatores, como atividade de água reduzida, presença de cloreto de sódio, nitrito de sódio e pH baixo, 
que poderiam inibir a multiplicação de muitos microrganismos, deve-se considerar a possibilidade de sobrevivência de patógenos como Staphylococcus coagulase positiva, Salmonella, entre outros, no produto final, uma vez que este tipo de produto não sofre tratamento térmico. No que se refere a produtos embutidos, derivados da industrialização da carne de suínos, a contaminação por salmonelas tem sido demonstrada em produtos crus, cozidos ou defumados, com um percentual variando entre 0 e $38 \%$ (OLIVEIRA, 1984).

Uma particularidade observada em embutidos fermentados produzidos por pequenas e médias indústrias do Paraná é a não utilização de culturas iniciadoras. O processo de fermentação nesses produtos geralmente se dá por microbiota intrínseca da própria matéria prima. Este tipo de fermentação natural leva a uma despadronização da queda do $\mathrm{pH}$, o que pode favorecer a sobrevivência e multiplicação de microrganismos indesejáveis, como por exemplo, Salmonella sp. Toxinfecções por Salmonella sp. assumem um caráter especial, pois a presença do microrganismo no alimento não é denunciada pelo alteração do aspecto, sabor ou outras características visíveis (MAGNANI, 2000).

Considerando o exposto, este estudo teve objetivo de avaliar a qualidade microbiológica de salames produzidos e comercializados na região oeste do Paraná, com relação à enumeração de microrganismos indicadores e pesquisa de Salmonella sp.

\section{Material e Métodos}

Obtenção das amostras de salames no comércio varejista de Palotina, PR;

Durante os anos de 2001 e 2002, trinta e quatro (n=34) amostras de salames industriais foram coletadas aleatoriamente em distintos pontos de venda do produto na cidade de Palotina e transportadas nas mesmas condições de comercialização até o Laboratório de Controle Microbiológico de Água e Alimentos (LACOMA) da Universidade Federal do Paraná, Campus Palotina, onde foram armazenadas em geladeira até o início das análises.

\section{Coleta asséptica da unidade analítica}

Foram pesadas, assepticamente, em sacos plásticos estéreis, 25g da amostra em duplicata, obtendo-se assim duas subamostras.

A primeira subamostra foi utilizada para a pesquisa de Salmonella sp. Na segunda subamostra foram adicionados $225 \mathrm{~mL}$ de solução salina $0,85 \%$, e a seguir a mesma foi 
homogeneizada em "stomacher" durante dois minutos para obtenção da diluição $10^{-1}$. A partir dessa diluição procederam-se as demais diluições decimais seriadas $\left(10^{-2}, 10^{-3}, 10^{-4}\right.$ e $\left.10^{-5}\right)$.

\section{Determinação de coliformes totais pelo número mais provável (NMP)}

Foi realizada a técnica do número mais provável $\left(\mathrm{NMP} \cdot \mathrm{g}^{-1}\right)$ utilizando-se as diluições $10^{-1}$, $10^{-2}$ e $10^{-3}$ (técnica dos tubos múltiplos), empregando-se o caldo Lauril Sulfato Triptose (LST) com tubos de Durham invertidos (VANDERZANT e SPLITTSTOESSER, 1992). Foram numeradas e identificadas, três séries de tubos de ensaio (para as diluições $10^{-1}, 10^{-2}$ e $10^{-3}$ ), cada série contendo três tubos. Transferiu-se $1 \mathrm{~mL}$ da diluição $10^{-1}$ para cada um dos três tubos pertencentes a primeira série de tubos contendo o LST. Transferiu-se, igualmente, $1 \mathrm{~mL}$ da diluição $10^{-2}$ para cada um dos três tubos da segunda série. O mesmo procedimento foi realizado para a diluição $10^{-3}$. A bateria de tubos foi então incubada em estufa a $35^{\circ} \mathrm{C}$ por $48 \mathrm{~h}$. No final do período de incubação verificou-se a turvação do meio de cultura (LST) e a fermentação da lactose identificada pela presença de gás, nos tubos de Durham, caracterizando a positividade para coliformes totais.

O resultado foi interpretado pela combinação de tubos positivos de acordo com a tabela do NMP (GARTHRIGHT, 2001).

\section{Determinação de coliformes termotolerantes pelo número mais provável (NMP)}

Utilizou-se a técnica dos tubos múltiplos, empregando-se o caldo Escherichia coli (EC) (VANDERZANT e SPLITTSTOESSER, 1992). Cada tubo de caldo EC continha $9 \mathrm{~mL}$ de meio de cultura e tubos de Durham imersos. Para cada tubo positivo no caldo LST (meio turvo com formação de gás), inoculou-se, com do auxílio de alça de platina, uma alçada em caldo EC. Essa bateria de caldo EC foi então incubada em banho maria a $44,5^{\circ} \mathrm{C} \pm 0,5^{\circ} \mathrm{C}$ durante $24 \mathrm{~h}$. Ao final desse tempo, foram considerados positivos os tubos turvos e com gás, evidenciado pelo aprisionamento do mesmo dentro dos tubos de Durham.

O resultado foi interpretado pela combinação de tubos positivos de acordo com a tabela do NMP (GARTHRIGHT, 2001).

\section{Contagem de Staphylococcus coagulase positiva;}

Foi utilizada a técnica do espalhamento superficial ("spread plate"), semeando-se $0,1 \mathrm{~mL}$ de cada uma das diluições $10^{-2}, 10^{-3}$ e $10^{-4}$, espalhando-se o inóculo com auxílio do bastão de Drigalsky, em meio Baird-Parker adicionado de 5\% de emulsão gema de ovo e $1 \%$ de telurito de potássio e incubados a $35^{\circ} \mathrm{C}$ por 48 h. Após o período de incubação, observou-se colônias típicas de Staphylococcus sp., as quais apresentavam-se como circulares, pequenas, negras, convexas e brilhantes, circundadas por dois halos, um opaco (mais interno) correspondente da ação da 
lecitinase sobre a gema do ovo dando origem a um precipitado de ácidos graxos livres e um halo transparente (mais externo), devido a lipólise. Colônias típicas e atípicas foram repicadas para o caldo de enriquecimento Brain Heart Infusion (BHI) e incubados a $35{ }^{\circ} \mathrm{C}$ por 24 horas. Então procedeu-se o teste da coagulase livre (em tubo). Este teste consistiu em pipetar assepticamente 0,2 $\mathrm{mL}$ do crescimento em caldo BHI para um tubo previamente esterilizado contendo $0,25 \mathrm{~mL}$ de plasma de coelho com EDTA. Incubou-se em estufa a $35^{\circ} \mathrm{C}$ por $6 \mathrm{~h}$, observando, a cada 30 minutos, a formação de coágulo pela ação da enzima coagulase, que indica a positividade do teste.

\section{Pesquisa de Salmonella sp.;}

À segunda subamostra foram adicionados $225 \mathrm{~mL}$ de água peptonada tamponada (APT), compondo assim o pré-enriquecimento ou enriquecimento não seletivo, o qual foi incubado a 35 ${ }^{\circ} \mathrm{C} / 18$-24 horas. Ao término desse período, transferiu-se com auxílio de pipeta estéril $1 \mathrm{~mL}$ do préenriquecimento para o caldo Tetrationato (TT) (incubação em $35^{\circ} \mathrm{C} / 24$ horas) e $0,1 \mathrm{~mL}$ para o caldo Rappaport Vassiliadis (RV) (incubação em $42 \quad{ }^{\circ} \mathrm{C} / 24$ horas) compondo assim o enriquecimento seletivo. A partir desses caldos repicou-se para os ágares Xilose Lisina Desoxicolato (XLD) e Bismuto de Sulfito (BS), incubando a $35^{\circ} \mathrm{C}$ por $24-48$ horas com o objetivo de se obter colônias típicas isoladas. Essas colônias no meio XLD apresentavam-se vermelhas com o centro negro. No BS as colônias apresentavam-se negras e com um brilho metálico após um mínimo de 18 horas de incubação. Após 48 horas apresentavam coloração negra uniforme. As colônias típicas eram repicadas para os meios Lisina Iron Ágar (LIA) e Triple Sugar Iron (TSI), com incubação em $35{ }^{\circ} \mathrm{C}$ durante $24 \mathrm{~h}$. No LIA, para uma reação característica de Salmonella sp., observou-se a superfície e a base alcalinas, evidenciadas pela permanência da cor do meio (violeta), e a produção de ácido sulfídrico $\left(\mathrm{H}_{2} \mathrm{~S}\right)$. No meio TSI, observou-se uma superfície alcalina (mudança da cor laranja para violeta), uma base ácida (mudança de cor de laranja para amarelo) e também a produção de $\mathrm{H}_{2} \mathrm{~S}$. Considerou-se, para fins de interpretação de suspeita de presença de Salmonella sp., as reações características dos meios de cultura citados acima.

Procedeu-se então, o teste da urease a partir dos tubos de TSI e LIA característicos para Salmonella sp. Com auxílio da alça de platina foi repicado uma amostra da colônia em caldo uréia com posterior incubação a $35^{\circ} \mathrm{C}$ por 24 horas. Ao término desse tempo observou-se a permanência (prova negativa) ou a mudança de cor (prova positiva) do meio indicando a produção ou não da referida enzima.

Dos tubos positivos para a urease foram realizados testes sorológicos em soro polivalente anti Salmonella (somático e flagelar). Em lâmina de vidro colocou-se uma gota de soro com uma alçada da colônia, a partir dos meios TSI ou LIA. Observou-se aglutinação pela formação do complexo antígeno-anticorpo caracterizando a positividade do teste. 
Para as amostras suspeitas de Salmonella sp., que tiveram resultado característico na urease e sorologia, foi realizado o teste bioquímico (IMViC) para a confirmação da presença da bactéria. Esse teste consistiu em uma bateria de 4 tubos contendo no primeiro caldo triptose, caldo Vermelho de Metila/Voges Proskauer - VM/VP - no segundo e terceiro tubos e ágar citrato de Simmons no último tubo. A partir do meio TSI ou LIA, repicou-se com auxílio da alça de platina para os meios citados acima. A incubação foi realizada a $35{ }^{\circ} \mathrm{C} / 24 \mathrm{~h}$ para então adicionar os reagentes (reagente de Kovacs para o teste do Indol no primeiro tubo, vermelho de metila para caldo VM/VP no segundo tubo, $\alpha$-naftol $5 \%$ e $\mathrm{KOH}$ a $40 \%$ para VM/VP no terceiro tubo). O teste do citrato é verificado pela mudança de cor do meio de verde para azul no caso de positividade. A sequência de resultados considerados típicos para Salmonella sp. foram negativo para o teste do indol e Voges Proskauer e positivo para os testes de Vermelho de Metila e Citrato de Simmons.

Expressou-se, de acordo com a combinação de resultados, presença ou ausência de Salmonella sp. em 25g de salame analisados.

Os resultados das análises foram comparados com a Resolução 12 do Ministério da Saúde, que determina os padrões microbiológicos para alimentos (BRASIL, 2001), seguindo as técnicas recomendadas pela APHA (American Public Health Association) e compiladas por Vanderzant e Splittstoesser (1992).

\section{Resultados e discussão}

A RDC nº 12 do Ministério da Saúde (BRASIL, 2001), estabelece para produtos cárneos defumados o limite máximo de $10^{3} \mathrm{NMP} / \mathrm{g}$ para coliformes termotolerantes, 5,0 x $10^{3} \mathrm{UFC} / \mathrm{g}$ para Staphylococcus coagulase positiva e ausência de Salmonella sp. em $25 \mathrm{~g}$ de alimento.

Comparando os resultados obtidos com a legislação nacional vigente (BRASIL, 2001), pode-se observar que em 21 das 34 amostras analisadas (61,8\%), as contagens de Staphylococcus coagulase positiva superaram o limite máximo estabelecido. Considerando que a contagem de Staphylococcus tem significado como indicador de manipulação inadequada e como microrganismo causador de ETA, é possível supor que as altas contagens obtidas estejam relacionadas a uma precária condição de manipulação e ainda acena com a possibilidade destes produtos serem potencialmente capazes de causar ETA, uma vez que Staphylococcus acima de $10^{5} \mathrm{UFC} / \mathrm{g}$ podem produzir enterotoxinas suficiente para causar doença no consumidor.

Os resultados das enumerações de coliformes totais, termotolerantes, Staphylococcus coagulase positiva e pesquisa de Salmonella sp. nas trinta e quatro amostras são demonstrados na Tabela 1. 
Tabela 1 - Resultados das análises microbiológicas realizadas em salames produzidos e comercializados na região Oeste do Paraná, 2002

\begin{tabular}{|c|c|c|c|c|}
\hline \multirow{2}{*}{ Amostra } & \multicolumn{2}{|c|}{ Contagem de coliformes (NMP.g $\left.{ }^{-1}\right)$} & \multirow{2}{*}{$\begin{array}{c}\text { Contagem de } \\
\text { Staphylococcus coagulase } \\
\text { positiva (UFC.g }{ }^{-1} \text { ) }\end{array}$} & \multirow{2}{*}{$\begin{array}{c}\text { Pesquisa de } \\
\text { Samonella sp. em 25g }\end{array}$} \\
\hline & Totais & Termotolerantes & & \\
\hline 01 & $<1,8$ & $<1,8$ & $1,0 \times 10^{3}$ & Ausência \\
\hline 02 & 1100 & 93 & $1,6 \times 10^{6}$ & Ausência \\
\hline 03 & 93 & 23 & $1,0 \times 10^{3}$ & Ausência \\
\hline 04 & $<1,8$ & $<1,8$ & $2,1 \times 10^{5}$ & Ausência \\
\hline 05 & $>1100$ & $>1100$ & $2,7 \times 10^{7}$ & Ausência \\
\hline 06 & 9,2 & 3,6 & $2,8 \times 10^{5}$ & Ausência \\
\hline 07 & $<1,8$ & $<1,8$ & $1,0 \times 10^{4}$ & Ausência \\
\hline 08 & 3,6 & $<3$ & $1,0 \times 10^{3}$ & Ausência \\
\hline 09 & 34 & 3,6 & $2,8 \times 10^{7}$ & Presença \\
\hline 10 & $>1600$ & 350 & $1,4 \times 10^{4}$ & Ausência \\
\hline 11 & 350 & 13 & $1,0 \times 10^{4}$ & Ausência \\
\hline 12 & 110 & 3,6 & $3,1 \times 10^{6}$ & Ausência \\
\hline 13 & $>1600$ & 49 & $1,0 \times 10^{3}$ & Ausência \\
\hline 14 & 33 & 4,5 & $1,0 \times 10^{4}$ & Ausência \\
\hline 15 & 540 & 79 & $1,8 \times 10^{5}$ & Ausência \\
\hline 16 & $>2400$ & 34 & $1,0 \times 10^{3}$ & Ausência \\
\hline 17 & $<3,0$ & $<3,0$ & $1,0 \times 10^{2}$ & Ausência \\
\hline 18 & $>2400$ & $>2400$ & $1,0 \times 10^{4}$ & Presença \\
\hline 19 & $<3,0$ & $<3,0$ & $1,0 \times 10^{2}$ & Ausência \\
\hline 20 & $\geq 2400$ & 11 & $1,0 \times 10^{2}$ & Ausência \\
\hline 21 & 23 & 23 & $1,0 \times 10^{2}$ & Ausência \\
\hline 22 & 47 & 4,5 & $1,0 \times 10^{4}$ & Ausência \\
\hline 23 & 49 & 7,8 & $4,0 \times 10^{7}$ & Ausência \\
\hline 24 & 920 & 22 & $8,3 \times 10^{4}$ & Ausência \\
\hline 25 & 130 & 13 & $1,0 \times 10^{5}$ & Ausência \\
\hline 26 & 130 & 11 & $1,0 \times 10^{3}$ & Ausência \\
\hline 27 & $<1,8$ & $<1,8$ & $1,0 \times 10^{5}$ & Ausência \\
\hline 28 & 540 & 17 & $1,0 \times 10^{5}$ & Ausência \\
\hline 29 & 63 & 7,8 & $1,0 \times 10^{3}$ & Ausência \\
\hline 30 & 920 & 130 & $1,0 \times 10^{3}$ & Ausência \\
\hline 31 & 350 & 110 & $1,0 \times 10^{5}$ & Ausência \\
\hline 32 & 920 & 24 & $1,0 \times 10^{4}$ & Ausência \\
\hline 33 & 540 & 33 & $1,0 \times 10^{3}$ & Ausência \\
\hline 34 & 1600 & 170 & $2,7 \times 10^{6}$ & Ausência \\
\hline
\end{tabular}

Observou-se em duas (5,9\%) amostras contagem acima do estabelecido pela legislação (BRASIL, 2001), para coliformes termotolerantes, o que enquadra tais amostras como produto em condições higiênico sanitárias insatisfatórias.

Salmonella sp. foi encontrada em duas (5,9\%) amostras de salames produzidas e comercializadas na região oeste do Paraná, índice semelhante ao relatado por Magnani et al. (2000), na cidade de Chapecó, SC, os quais detectaram a presença de Salmonella em 6\% dos salames coloniais por eles analisados. Estes mesmos autores detectaram coliformes fecais em $72 \%$ das amostras, índice superior ao relatado neste estudo.

Observa-se uma variação na presença de Salmonella sp. em embutidos cárneos e carne ao longo de vários anos e regiões geográficas de isolamento. Como exemplos podem ser citados os 
trabalhos de Oliveira, (1984), em Curitiba, PR, que não encontrou Salmonella sp. em produtos embutidos e submetidos à processos de defumação ou cocção; Giombelli, (2001), que encontrou Salmonella sp. em 50,5\% das amostras de carne in natura analisadas em Chapecó, SC. Em Cuiabá MT, no período compreendido entre 1990 e 1991, foi isolada a Salmonella em 20\% das amostras de embutidos cárneos analisados (REIS et al., 1995); Sabioni (1999), encontrou 3\% de positividade para Salmonella sp. em linguiça do tipo frescal. No entanto, Chaves et al. (2000), encontraram um índice de $10 \%$ para a mesma bactéria em linguiça frescal suína; Sousa, (2000) analisando carne moída na cidade de Macapá, PA não detectou Salmonella sp., porém 6,6\% das amostras estavam contaminadas com Staphylococcus aureus e destes, apenas 1 amostra (3,3 \%) com contagem superior a $300 \times 10^{3} \mathrm{UFC} / \mathrm{g}$ e $26,6 \%$ das amostras de carne contendo coliformes fecais com níveis acima de $10^{3} \mathrm{NMP} / \mathrm{g}$, ou seja, fora do padrão. Já em Pelotas, RS, Tessemann et al. (2008) detectaram Salmonella em $80 \%$ dos cortes de carne suína por eles analisados.

Em outras regiões do mundo o índice também é muito variado, como pode ser observado nos estudos conduzidos por Madden et al., 2001, que detectaram Salmonella em 1,5\% das carcaças bovinas abatidas na Irlanda do Norte; em amostras de chouriço, analisadas na Cidade do México, foi detectada a presença de Salmonella em 2,4\% das amostras (SALGADO et al., 1999). No período entre 1988 a 1992 ocorreram 549 surtos e 21.177 casos de salmonelose nos EUA, tendo sido Salmonella o patógeno que esteve envolvido em maior número de surtos e casos neste período (BEAN et al., 1997). Segundo dados estimados pelo Center for Disease and Control Prevention (CDC-EUA) ocorrem, anualmente, 1.341 .873 casos de salmonelose veiculados por alimentos, o que representa 9,7\% do total de ETAs ao ano. Estima-se também 15.608 hospitalizações/ano, representando $25,8 \%$ do total. São estimadas 553 mortes (30,6\% do total de mortes). Salmonella, Listeria, Toxoplasma, Norwalk-like viruses, Campylobacter e E. coli O157:H7 representam juntas $90 \%$ do total de mortes por ETA nos EUA (MEAD et al., 1999).

Com o presente estudo foi possível evidenciar falhas no processamento do alimento e que devem ser melhoradas as condições higiênico sanitárias dos locais de abate, armazenamento e transporte da carne assim como dos manipuladores dos alimentos. Além disso, práticas de higiene inadequadas ou inexistentes durante obtenção, transporte e manipulação da carne, a presença de manipuladores portadores de bactérias como Salmonella sp. e Staphylococcus coagulase positiva, favorecem a contaminação da carne (RITTER, 2001).

\section{Conclusão}

Através da contaminação observada no salame produzido e comercializado na região oeste do Paraná, sugere-se más condições de higiene no momento da fabricação. 


\begin{abstract}
The aim of this study was to characterize salami produced and marketed in the western region of Paraná, through an enumeration of indicator micoorganisms and Salmonella sp. Thirty-four $(n=34)$ samples of industrialized salamis were acquired in Palotina, located in western Paraná, and subjected to microbiological analysis for enumeration of coagulase positive Staphylococcus, total coliform $\left(35^{\circ} \mathrm{C}\right)$ and fecal coliform $\left(45^{\circ} \mathrm{C}\right)$ and research Salmonella sp. Observed $61.8 \%$ of samples contaminated with coagulase positive Staphylococcus beyond that established in the RDC 12 (ANVISA). It was found 5.9\% of samples contaminated with fecal coliform and 5.9\% of samples contaminated with Salmonella sp. Through the contamination found in salami produced and marketed in the western region of Paraná, suggest poor hygiene conditions at the time of manufacture.
\end{abstract}

Key-words: sausage, contamination, hygiene

\title{
Referências
}

BACUS, J. Meat and Poultry Microbiology. In: PEARSON, A. M., DUTSON, T. R. Advances in meat research. Westport: AVI, 1986. v. 2, cap. 4, p. $69-164$.

BEAN, N. H., GOULDING, J. S., DANIELS, M. T., ANGULO, F. J. Surveillance for foodborne disease outbreaks United States, 1988-1992. Journal of Food Protection, Ames, v. 60, n. 10, p. 1265-1286, 1997.

BRASIL. Ministério da Saúde. Resolução-RDC n 12, de 02 de Janeiro de 2001. Regulamento técnico sobre padrões microbiológicos para alimentos. Diário Oficial da República Federativa do Brasil, Brasília, DF, 10 jan. 2001, Seção I, n. 7-E, p. 46-53.

BRASIL. Ministério da Agricultura. Instrução Informativa de 03/08/2000 publicada no Diário Oficial da União, de 03/08/2000 - Regulamento Técnico de Identidade e Qualidade de Salame. AnexoV.

CHAVES, G. M. C., GONÇALVES, P. M. R., FRANCO, R. M., CARVALHO, J. C. A. P., Avaliação bacteriológica de linguica frescal suína comercializada no Município do Rio de Janeiro, RJ. Higiene Alimentar v. 14, n. 73, p. 48-52, 2000 .

DOYLE, M.P. The emergence of new agents of foodborne disease in the 1980s. Food Research International, v. 27, p. 219-226, 1994. D.O.I:10.1016/0963-9969(94)90087-6

FRANCO, B. D. G .M., LANDGRAF, M. Microbiologia dos alimentos. Atheneu: São Paulo, 182p. 2002.

GARTHRIGHT, W. E. US Food and Drug Administration. Center for Disease Control and Prevention. Bacteriological Analytical Manual Online. January, 2001. Disponível em: http://www.vm.cfsan.fda.gov/ ebam/bam-toc.html, ACESSO em 12/03/2002.

GIOMBELLI, A., SILVA, N. L., Avaliação do método tradicional para detecção de Salmonella sp. em carnes in natura. Higiene Alimentar v. 15, n. 87, p. 63-66, 2001.

LEITÃO, M. F. F. Controle do desenvolvimento microbiano no processamento industrial da carne e produtos cárneos. Boletim do Instituto de Tecnologia de Alimentos, Campinas, v. 21, n. 1, p. 21-39, 1984.

MADDEN, R.H., ESPIE, E., MORAN, L., McBRIDE, J., SCATES, P. Occurrence of Eschericha coli O157:H7, Listeria monocytogenes, Salmonella and Campylobacter spp. on beef carcesses in Notthern Ireland. Meat Science, v. 58, p. 343-346, 2001. D.O.I.:10.1016/S0309-1740(00)00153-4

MAGNANI, A.L., GIOMBELLI, A., SHUCK, M.S., BUSATO, M.A., SILVA, N.L. Incidência de Salmonella e Escherichia coli em carne suína in natura e salame colonial, consumidos pela populaçäo de Chapecó - SC. Higiene alimentar, v. 14, n. 73, p. 44-47. 2000.

MEAD, P. S., SLUTSKER, L., DIETZ, V., McCAIG, L. F., BRESEE, J. S., SHAPIRO, C., GRIFFIN, P. M., TAUXE, R.V. Food-related illness and death in the United States. Emergingig Infection Diseases, Atlanta, v. 5, n. 5, p. 607-625, 1999. D.O.I:10.3201/eid0505.990502 
OliveirA, E. B., MIKOSZEWSKA, I., FILHO, A. M. S., FRANÇA, D. C. Sorotipos de Salmonella isolados em matadouros-frigoríficos. V - Presença em produtos embutidos. Brazilian Arquives of Biology and Tecnology. v. 27, n. 3, p. 299-304, 1984.

PELAYO, J. S., SARIDAKIS, H. O., Sorotipos de Salmonella isolados de produtos cárneos em Londrina - PR. Revista de Microbiologia, São Paulo, v. 19, n. 1, p. 17-21, jan/mar. 1988.

REIS, R. B., KRUGER, C. S., MACIEL, M. S. Salmonella spp. em produtos cárneos comercializados no município de Cuiabá-MT. Avaliação da metodologia de pesquisa. Modelos de resistência a drogas antimicrobianas. Ciência e Tecnologia de Alimentos, v. 15, n. 1, p. 74-78, 1995.

RITTER, R., SANTOS, D., BERGMANN, G. P. Contaminação bacteriana da carne moída bovina comercializada em bancas do mercado público de Porto Alegre, RS. Higiene Alimentar, v. 15, n. 85, p. 50-56, 2001.

SABIONI, J. G., MAIA, A. R. P., LEAL, J. A. Avaliação microbiológica de linguica frescal comercializada na cidade de Ouro Preto, MG. Higiene Alimentar, v.13, n. 61, p. 110-113, 1999.

SALGADO, J.M., ARANGO, C.J.J., NÚÑES, J.F.E., MORA, P.M. Salmonella sp en tres tipos de chorizos, como peligro dentro de un sistema de análisis de riesgos e identificación de puntos críticos de control (HACCP), en una empacadora de la ciudad de México Veterinaria México, v. 30, n. 2, p. 157-65, 1999.

SOUSA, C. L., PEIXOTO, M. R. S., SILVA, E. C., OLIVEIRA, R. I. Avaliação da Qualidade microbiológica e físicoquimica da carne bovina moída em açougues do município de Macapá - AP. Higiene Alimentar, v. 14, n. 72, p. 60-65, 2000.

TESSMANN, C. ZOCCHE, F., LIMA, A. S., BASSANI, M., LOPES, G. V., SILVA, W. P. Ocorrência e perfil de sensibilidade de Salmonella ssp. Isolada em cortes de carne suína comercializados em feiras-livre de Pelotas (RS). Boletim do Ceppa, v. 26, n. 2, p. 307-313, 2008.

VANDERZANT, C., SPLITTSTOESSER, D.F. Compendium of methods for the microbiological examination of foods. Washington: APHA, 1992.

Submetido em 06 ago. 2010; Revisão submetida pelos autores em 10 jan. 2011; Aceito para publicação em 30 jun.2011. 